\title{
GERÊNCIA DOS SERVIÇOS DE ENFERMAGEM: UM ESTUDO BIBLIOGRÁFICO
}

\author{
NURSING SERVICE MANAGEMENT: A BIBLIOGRAPHICAL STUDY
}

\section{GERENCIA DE LOS SEVICIOS DE ENFERMERÍA: UN ESTUDIO BIBLIOGRÁFICO}

\section{Ana Beatriz de Almeida Aguiar ${ }^{1}$, Raquel da Silva Barros Costa $^{1}$, Claci Fátima Weirich ${ }^{2}$, Ana Lúcia Queiroz Bezerra $^{3}$}

RESUMO: Este estudo tem como objetivo realizar levantamento de artigos científicos sobre administração dos serviços de Enfermagem, publicados na Revista Brasileira de Enfermagem e analisar as propostas e tendências de gerência nos serviços de saúde, com vistas a subsidiar as ações de Enfermagem nesta área. Trata-se de uma pesquisa bibliográfica, desenvolvida com base em material já elaborado. Percebemos que o assunto é pouco divulgado no meio científico. Além disso, todas as publicações tiveram a participação de docentes, o que mostra pouco envolvimento dos enfermeiros de serviços com pesquisa. Nosso estudo deixa alguns pontos importantes para reflexão acerca da formação de enfermeiros com competência para gerenciar serviços de saúde e, conseqüentemente assistir clientes com mais dignidade e qualidade a que têm direito.

PALAVRAS - CHAVE: Gerência; Serviços de Enfermagem; Gestão em Saúde.

ABSTRACT: This paper aim to identify scientific papers about management of Nursing services issue, published in the Revista Brasileira de Enfermagem (Brazilian Nursing Journal) as well as analizing management trends and proposals concerning health care services, in order to foster nursing actions in this area. This is a bibliographical research, based on bibliographic references. We noticed that this is an issue not much discussed in the scientific scene. Furthermore, all publications had the participation of teachers, which shows little involvement of the practitioners in research. This study shows some important issues for reflection regarding nurse's background with competence for managing health care services, thus assisting clients with more dignity and quality considered as their rights.

KEY WORDS: Management; Nursing Services; Health Management.

RESUMEN: Este estudio tiene como objetivo de realizar un levantamiento de artículos científicos sobre administración de los servicios de Enfermería, publicados en la Revista Brasileña de Enfermeria y analizar las propuestas y tendencias de gerencia en los servicios de salud, con vistas a subsidiar las acciones de Enfermería en esta area. Se trata de una investigación bibliográfica, desenvuelta con base en material ya elaborado. Vimos que el asunto es poco difundido en el medio científico. Además de eso, todas las publicaciones tuvieron la participación de docentes, lo que muestra poco envolvimento de los enfermeros de servicios con investigación. Nuestro estudio deja algunos puntos importantes para reflexión en lo que se refiere a la formación de enfermos con competencia para gerenciar servicios de salud y consecuentemente dar asistencia a los clientes con más dignidad y calidad a la cual tienen derecho.

PALABRAS CLAVE: Gerencia; Servicios de Enfermería; Gestión en Salud.

${ }^{1}$ Estudante de Graduação em Enfermagem na Universidade Federal de Goiás. Goiânia, GO. anabeatrizenf@yahoo.com.br / kaquelen@yahoo.com.br.

${ }^{2}$ Enfermeira. Doutoranda no Programa Multiinstitucional de Pósgraduação em Ciências da Saúde - Rede Centro Oeste - Convênio UnB/UFG/UFMS. Professora Assistente da Faculdade de Enfermagem da Universidade Federal de Goiás. Goiânia, GO. claci@cultura.com.br

${ }^{3}$ Enfermeira. Doutora em Enfermagem. Professora Adjunta da Faculdade de Enfermagem da Universidade Federal de Goiás. Goiânia GO. analuciaqueiroz@uol.com.br 


\section{INTRODUÇÃO}

As inovações tecnológicas têm provocado importantes mudanças no contexto empresarial, com reflexos no mercado de trabalho, em especial, na área de saúde, reduzindo os cargos, aumentando as diferenças salariais, criando novas profissões e descredenciando outras, constituindo-se em um desafio para o homem moderno que necessita promover sua adaptação, seu desenvolvimento pessoal e profissional para conviver nessa nova realidade (MUNARI et al, 2003).

Nessa perspectiva, a enfermagem passa por um repensar e uma redefinição de suas funções, de maneira a assegurar seu papel e seu compromisso com a sociedade que, nesse momento, aspira por maior qualidade na prestação da assistência à sua saúde (SIMÔES \& FÁVERO, 2000).

É no contexto dessas mudanças que devemos situar as novas perspectivas da enfermagem, das políticas de saúde e do trabalho gerencial. O Sistema Único de Saúde com suas fortes implicações sóciopolíticas, econômicas e culturais compõem um cenário no qual a gerência no trabalho do enfermeiro é uma característica essencial no enfrentamento dos desafios propostos por esse novo sistema de saúde. Essas modificações invariavelmente colocam não só novas demandas para a profissão como encerram novas determinações na própria organização e dinâmica de seu processo de trabalho administrativo (AZEVEDO, 2000).

Atualmente, com a ênfase na necessidade de reconstrução dos modelos de gestão, estão surgindo novas abordagens gerenciais como a gerência participativa e os programas de qualidade que preconizam, dentre outras, a descentralização das decisões e aproximação de todos os elementos da equipe de trabalho, oferecendo aos mesmos, oportunidades de participarem efetivamente da discussão e aperfeiçoamento constantes do processo de trabalho, ou seja, é delegada às equipes, autonomia para desenvolver novos projetos e métodos de trabalho, formular políticas de pessoal bem como sugerir novas diretrizes para a organização (FERNANDES et al, 2003).

A inserção do Enfermeiro nesse contexto de mudanças, acompanhando a evolução do mundo globalizado, faz-se necessária, para a busca do progresso de seu conhecimento por meio da implantação da política do saber e fazer crítico, que certamente, o tornaria um profissional capaz de resolver desafios do cotidiano.

Como acadêmicas de enfermagem, temos sentido a necessidade urgente de revermos nosso aprendizado a respeito da formação do enfermeiro como gerente de serviços de saúde, tendo em vista os desafios postos pelo panorama atual na atenção em saúde.

Por compreender a importância do trabalho gerencial dos enfermeiros nas instituições de saúde, poderemos contribuir para a reflexão acerca da gerência em enfermagem na perspectiva de destacarmos as propostas e tendências relevantes para a construção dessa prática profissional, em consonância com os princípios da administração contemporânea.

Tivemos como objetivos neste estudo identificar os artigos científicos sobre gerência/administração dos serviços de enfermagem, publicados na Revista Brasileira de Enfermagem (REBEn), nos anos de 2003 e 2004; analisar as propostas e tendências de gerenciamento em enfermagem nos serviços de saúde, com vistas a subsidiar as ações do enfermeiro nesta área.

\section{METODOLOGIA}

Trata-se de uma pesquisa bibliográfica, retrospectiva e constituída de artigos científicos acerca da temática administração e gerência de enfermagem nos serviços de saúde (GIL, 2002).

O estudo foi desenvolvido na Faculdade de Enfermagem da Universidade Federal de Goiás UFG, situada em Goiânia-GO, no período de maio de 2004 a julho de 2005.

Foram utilizados como fontes de informações as publicações sobre a temática encontradas na Revista Brasileira de Enfermagem (REBEn), nos anos 2003 e 2004; identificando neste período, as propostas e tendências de gerência de enfermagem contemporânea nos serviços de saúde.

Foram utilizados como descritores os termos: administração, gerência, gestão, perfil do enfermeiro gerente, liderança e tendências e propostas para gerência, os quais foram identificados nos títulos dos artigos.

Os resumos dos artigos que atendiam aos critérios de inclusão foram selecionados e lidos integralmente.

Após repetidas leituras dos artigos foram identificadas as categorias previamente definidas: caracterização dos autores; conceitos e funções gerenciais; perfil do enfermeiro gerente; propostas e tendências de gerência contemporânea.

As categorias foram estabelecidas antes do trabalho de campo, na fase exploratória, o que é pertinente, pois segundo MINAYO (1996), o pesquisador pode definir as categorias a serem investigadas antes do trabalho de campo e após a coleta de dados, ele também poderá reformulá-las visando à classificação dos dados encontrados em seu trabalho de campo.

\section{RESULTADOS E DISCUSSÕES}

A REBEn publicou nos anos 2003-2004, 13 artigos referentes à temática gerenciamento em serviços de enfermagem, conforme os descritores préestabelecidos, os quais foram agrupados nas categorias e analisados individualmente, de forma qualitativa com respaldo da literatura. 


\section{Caracterização dos autores}

Esta categoria está demonstrada no quadro abaixo, onde estão identificados todos os autores dos artigos e caracterizados conforme sua formação profissional, títulação e o ano de publicação.

Do total de artigos publicados, somente um corresponde ao ano de 2003 e 12 ao ano de 2004 , sendo 11, incluídos em uma mesma edição temática da revista. Isso mostra a escassez de publicações sobre este tema, sendo pertinente as edições temáticas para o equilíbrio de informações nas diversas áreas.

Todas as publicações tiveram a participação de docentes, o que mostra pouca participação dos enfermeiros de serviços com pesquisa.

Quadro 1- Caracterização dos autores - REBEn - 2003 - 2004. Goiânia, 2005.

\begin{tabular}{|c|c|c|c|}
\hline AUTORES & FORMAÇÃO & ANO & "TíTULO \\
\hline $\begin{array}{l}\text { Alves, M. } \\
\text { Penna, CMM. } \\
\text { Brito, MJM. }\end{array}$ & $\begin{array}{l}\text { Enfermeira/doutora /professora adjunto IV } \\
\text { Enfermeira/doutora /professora adjunto I } \\
\text { Enfermeira/doutora / professora adjunto I }\end{array}$ & 2004 & $\begin{array}{l}\text { Perfil dos gerentes de } \\
\text { unidades básicas de saúde }\end{array}$ \\
\hline $\begin{array}{l}\text { Ciampone, } \mathrm{HI} \text {. } \\
\text { Kurgcgant, } \mathrm{P} \text {. }\end{array}$ & $\begin{array}{l}\text { Enfermeira/professora/livre docente } \\
\text { Enfermeira/professora titular }\end{array}$ & 2004 & $\begin{array}{l}\text { O Ensino de Administração } \\
\text { em Enfermagem no Brasil: o } \\
\text { processo de construção de } \\
\text { competências gerenciais }\end{array}$ \\
\hline $\begin{array}{l}\text { Gaidzinski, RR. } \\
\text { Peres, HHC. } \\
\text { Fernandes, MFP }\end{array}$ & $\begin{array}{l}\text { Enfermeira/professora associada } \\
\text { Enfermeira/professora doutora } \\
\text { Enfermeira/professora doutora } \\
\end{array}$ & 2004 & $\begin{array}{l}\text { Liderança: aprendizado } \\
\text { contínuo no gerenciamento } \\
\text { em enfermagem }\end{array}$ \\
\hline Greco, RM. & Enfermeira/professora doutora & 2004 & $\begin{array}{l}\text { Ensinando a administração } \\
\text { em enfermagem através da } \\
\text { Educação em Saúde }\end{array}$ \\
\hline $\begin{array}{l}\text { Guimarães, RM. } \\
\text { Muzi, CD. } \\
\text { Mauro, MYC. }\end{array}$ & $\begin{array}{l}\text { Interno de enfermagem } \\
\text { Interno de enfermagem } \\
\text { Enfermeira/doutora /professora titular }\end{array}$ & 2004 & $\begin{array}{l}\text { Tendências Modernas do } \\
\text { Trabalho da Enfermagem: o } \\
\text { caso das cooperativas }\end{array}$ \\
\hline $\begin{array}{l}\text { Magalhães, AMM. } \\
\text { Duarte, ERM. }\end{array}$ & $\begin{array}{l}\text { Enfermeira/mestre/professora assistente } \\
\text { Enfermeira/doutoranda/professora adjunto }\end{array}$ & 2004 & $\begin{array}{l}\text { Tendências gerenciais que } \\
\text { podem levar a enfermagem } \\
\text { a percorrer novos caminhos }\end{array}$ \\
\hline $\begin{array}{l}\text { Melo, MLC. } \\
\text { Nascimento, MAA. }\end{array}$ & $\begin{array}{l}\text { Enfermeira/mestre/ professora adjunto } \\
\text { Enfermeira/doutora /professora titular }\end{array}$ & 2003 & $\begin{array}{l}\text { Treinamento introdutório } \\
\text { para enfermeiras dirigentes: } \\
\text { possibilidades para gestão } \\
\text { do SUS }\end{array}$ \\
\hline $\begin{array}{l}\text { Munari, DB. } \\
\text { Bezerra, ALQ. }\end{array}$ & $\begin{array}{l}\text { Enfermeira/professora doutora/titular } \\
\text { Enfermeira/professora doutora/adjunto II }\end{array}$ & 2004 & $\begin{array}{l}\text { Inclusão da competência } \\
\text { interpessoal na formação do } \\
\text { enfermeiro como gestor }\end{array}$ \\
\hline $\begin{array}{l}\text { Oliveira, ACF. } \\
\text { Paz, ARA. } \\
\text { Telles, EAB.; } \\
\text { Leite, JL. } \\
\text { Stipp, MAC. }\end{array}$ & $\begin{array}{l}\text { Enfermeira/mestranda } \\
\text { Enfermeira/mestranda } \\
\text { Enfermeira/doutoranda/professora da graduação } \\
\text { Docente } \\
\text { Docente }\end{array}$ & 2004 & $\begin{array}{l}\text { Liderança e Enfermagem: } \\
\text { elementos para reflexão }\end{array}$ \\
\hline $\begin{array}{l}\text { Urbanetto, JS. } \\
\text { Capella, BB. }\end{array}$ & $\begin{array}{l}\text { Enfermeira/mestre/professora assistente } \\
\text { Enfermeira/doutora/professora aposentada }\end{array}$ & 2004 & $\begin{array}{l}\text { Processo de trabalho em } \\
\text { enfermagem: } \\
\text { Gerenciamento das relações } \\
\text { interpessoais }\end{array}$ \\
\hline $\begin{array}{l}\text { Vale, EG. } \\
\text { Guedes, MVC. }\end{array}$ & $\begin{array}{l}\text { Enfermeira/mestre em educação } \\
\text { Enfermeira/doutoranda/livre docente }\end{array}$ & 2004 & $\begin{array}{l}\text { Competências e habilidades } \\
\text { no ensino de administração } \\
\text { em Enfermagem à luz das } \\
\text { diretrizes curriculares } \\
\text { nacionais }\end{array}$ \\
\hline
\end{tabular}




\begin{tabular}{|c|c|c|c|}
\hline $\begin{array}{l}\text { Vaghetti, H. } \\
\text { Reis, D. } \\
\text { Kerber, NC. } \\
\text { Azambuja, E. } \\
\text { Fernandes, G. }\end{array}$ & $\begin{array}{l}\text { Enfermeira/mestre/professora da graduação } \\
\text { Acadêmica de enfermagem/FURG. } \\
\text { Enfermeira/doutoranda/professora da graduação } \\
\text { Enfermeira do Hospital Universitário/doutoranda } \\
\text { Enfermeira/doutoranda/professora da garduação }\end{array}$ & 2004 & $\begin{array}{l}\text { Percepções dos } \\
\text { Enfermeiros acerca das } \\
\text { ações administrativas em } \\
\text { seu processo de trabalho }\end{array}$ \\
\hline $\begin{array}{l}\text { Weirich, CF. } \\
\text { Munari, DB. } \\
\text { Bezerra, ALQ. }\end{array}$ & $\begin{array}{l}\text { Enfermeira/doutoranda/professora assistente } \\
\text { Enfermeira/doutora/professora titular } \\
\text { Enfermeira/doutora/professora adjunta }\end{array}$ & 2004 & $\begin{array}{l}\text { Endomarketing: ensaio } \\
\text { sobre possibilidades de } \\
\text { inovação na gestão em } \\
\text { enfermagem. }\end{array}$ \\
\hline
\end{tabular}

\section{Conceitos e funções gerenciais}

Nesta categoria analisamos os artigos que trazem conceitos e funções de gerência, definição de administração e de gerência do enfermeiro. Esses aspectos foram abordados por diversos autores.

Nos artigos pesquisados identificamos, o estudo de GRECO (2004), comentando que ao longo dos tempos, a palavra administração foi sendo substituída por gerência ou gestão que começou a ser discutido mundialmente como um recurso estratégico significando dentre outras coisas qualquer posição de direção ou chefia que tenha o objetivo de alcançar as metas previstas, através da aglutinação de esforços.

Esta crise do paradigma gerencial tradicional é baseada nos ensinamentos de Taylor, Fayol e seus seguidores modernos, que consideram uma boa organização a que possui um organograma detalhado, com ênfase na divisão do trabalho, no planejamento das funções, na descrição de cargos, nos manuais de tarefas e procedimentos, o que gera estruturas fixas, permanentes e rígidas (GRECO, 2004).

Entretanto, já se demonstrou que o planejamento e a organização tradicional são limitados, com baixa influência na produtividade. Mas, não se deve renunciar a este tipo de estrutura, é necessário que se vá além dela, através do uso da flexibilidade na organização e das condições de adaptação necessárias frente à mutação contínua da realidade que se vive.

$\mathrm{Na}$ enfermagem nos dias de hoje, gerência de unidade consiste na previsão, provisão, manutenção, controle de recursos materiais e humanos para o funcionamento do serviço, e gerência do cuidado que consiste no diagnóstico, planejamento, execução e avaliação da assistência, passando pela delegação das atividades, supervisão e orientação da equipe (GRECO, 2004). Assim os enfermeiros compreendem que administrar é cuidar e quando planejam, organizam, avaliam e coordenam, eles também estão cuidando (VAGHETTI et al, 2004).

A função gerencial pode ser conceituada como sendo um instrumento capaz de política e tecnicamente, organizar o processo de trabalho com o objetivo de torná-lo mais qualificado e produtivo na oferta de uma assistência de enfermagem universal, igualitária e integral (GRECO, 2004).

A gerência tem sido colocada como área estratégica para a transformação das práticas de saúde, pela sua posição intermediária entre as estruturas centrais, com poder de definição de diretrizes políticas e a prestação direta de serviços (MELO \& NASCIMENTO, 2003). Portanto, a gerência pode ser encarada como um instrumento para a efetivação das políticas, pois ela pode favorecer a manutenção ou a transformação de um determinado contexto.

Para GAIDZINSKI et al (2004), a gerência é como a arte de pensar, de decidir e de agir; a arte de fazer acontecer e de obter resultados. É um gerenciamento não como um processo apenas científico e racional, mas também como um processo de interação humana que the confere, portanto, uma dimensão psicológica, emocional e intuitiva.

A liderança é algo essencial no processo de trabalho gerencial do enfermeiro. Trata-se basicamente da coordenação de grupos, destacando que nas organizações, o significado atribuído à liderança, aos líderes e ao grupo, refletem a filosofia, a política de pessoal e as propostas de trabalho dessas organizações.

Cabe também à gerência um caráter articulador e integrativo, desde quando, a ação gerencial é determinada e determinante do processo de organização de serviços de saúde e fundamenta-se na efetivação de políticas sociais e, em especifico, as de saúde.

\section{Perfil do Enfermeiro Gerente}

Quanto ao perfil do enfermeiro gerente, competências e ferramentas que se deve utilizar para caracterizá-lo como líder e/ou gerente, foi abordado por maioria dos artigos.

$\mathrm{Na}$ Enfermagem, o termo competência refere-se à capacidade de conhecer e atuar sobre determinadas situações, envolve habilidades para desenvolver ações/atividades planejamento, implementação e avaliação, requerendo experiência para o fazer com qualidade.

Com esse entendimento às competências e habilidades específicas para a área de administração em enfermagem, desenvolvidas durante o processo de formação, devem privilegiar as condutas técnicocientificas, ético-politicas, sócio-educativas, de forma a permitir ao futuro profissional, reconhecer a saúde 
como direito, atuando para garantir a qualidade da assistência em todos os níveis de atenção à saúde, planejando, organizando, gerenciando e avaliando o processo de trabalho em enfermagem - saúde, em parceira com outros profissionais da mesma instituição.

De acordo com GRECO (2004), o mercado profissional espera que enfermeiro tenha capacidade para trabalhar com conflitos, enfrentar problemas, negociar, dialogar, argumentar, propor e alcançar mudanças, com estratégias que o aproximem da equipe e do cliente, contribuindo para a qualidade do cuidado, ou seja, espera-se do enfermeiro uma capacidade para gerenciar.

CIAMPONE \& KURCGANT (2004) afirmam que as diretrizes curriculares nacionais propõem que as competências específicas para preparar enfermeiros para o exercício da administração/gestão em enfermagem/saúde, são: planejamento e organização de serviços de enfermagem/saúde; gerência de serviços de enfermagem/saúde; gestão do trabalho enfermagem/saúde; planejamento e gestão financeira; gestão de recursos físicos e materiais; gestão da informação em enfermagem/saúde; desenvolvimento de política e planificação de propostas de atenção a enfermagem/saúde; gestão de processo de cuidar em enfermagem; elaboração de estratégias de avaliação, controle, auditoria e acreditação de serviços de saúde/enfermagem e coordenação da educação em serviço.

No entanto, de acordo com VALE \& GUEDES (2004), as competências definidas nas DCN (Diretrizes Curriculares Nacionais), apesar de atender a grande parte dos interesses da categoria, têm suscitado críticas e rejeições na sua compreensão e implementação, fato justificado pela concepção tecnicista de que a qualificação, muitas vezes, está atrelada a produção no modelo de organização capitalista do trabalho.

Em relação às dificuldades enfrentadas pelos gerentes, destaca-se a tensão existente entre o direito dos pacientes e as prerrogativas dos profissionais, a qual precisa ser equacionada pelo gestor como um dos pontos delicados e centrais da boa assistência à saúde (ALVES et al, 2004).

Assim, é imprescindível que os gerentes sejam capazes de minimizar as dificuldades a que estão expostos e aprendam a lidar com a nova situação, podendo desempenhar, satisfatoriamente, seu papel no processo de restauração do sistema de saúde.

Para atender às novas demandas impostas pelo SUS, o setor saúde tradicionalmente se ancorou no preparo técnico dos profissionais, exigindo um gerente com perfil diferenciado. Esse preparo enfatiza os processos diagnósticos e terapêuticos, relegando a um segundo plano a formação de um corpo gerencial adequadamente qualificado para atuar em contextos específicos, como os hospitais, as unidades secundárias e as unidades básicas de saúde. Os profissionais que, ao longo do tempo, se dividiam entre a clínica e a gerência, não mais correspondem ao perfil necessário.

Para solucionar essas dificuldades, consideramos o desenvolvimento da competência interpessoal uma ferramenta poderosa para transformar a prática gerencial do enfermeiro.

As atitudes e comportamentos frente às demandas atuais estão diretamente relacionados, não somente, à formação técnica do enfermeiro, mas à dinamização dos aspectos relacionais, que podem ser desenvolvidos a partir da ampliação da consciência de si mesmo, do controle da impulsividade, da persistência, motivação, empatia, zelo, habilidades sociais e resistência psicológica (MUNARI \& BEZERRA, 2004).

Portanto, muito além de capacitar profissionais de saúde, com competência técnica especializada, é necessário o desenvolvimento de pessoas comprometidas com o processo de gestão, que exige qualidades como a criatividade, a inovação, a intuição, a emoção, a capacidade de se relacionar e, principalmente, a capacidade de manter-se atualizado. É fundamental ainda, a estes profissionais, incorporar no conceito de qualidade do gestor a inteligência emocional, a competitividade, a parceria, a qualidade de vida no trabalho, e em particular, o desenvolvimento da competência interpessoal.

De acordo com BEZERRA \& MUNARI (2004), a competência interpessoal é constituída de um conjunto de aptidões e atitudes adquiridas, organicamente ligadas entre si. Essencialmente ela consiste em tornar o líder capaz de estabelecer com o outro relações interpessoais autênticas, de modo a criar um clima de grupo no interior dos quais as relações de trabalho possam evoluir de formais, estereotipadas e artificiais para funcionais, espontâneas e criativas.

O profissional que adquire sua competência interpessoal possui maior capacidade em lidar com problemas, desafios, em potencializar talentos e gerir trabalho em um clima de confiança e satisfação. Ele deixa de olhar apenas para si, podendo tornar-se capaz de compreender a complexidade das relações entre seres humanos, além disso, há uma melhora no desempenho global das organizações, gerando mais lucros e/ou serviços de melhor qualidade.

Nesse processo, a criatividade é fundamental, pois permite ao gestor a proposição de projetos que sejam inovadores na busca de novos resultados e novas formas de comportamento individual e organizacional. Com atitude inovadora, o gestor possibilita o desenvolvimento de atividades que se constituem desafios para a criatividade individual e coletiva. A aceitação de novas idéias leva a ruptura de práticas pré-estabelecidas, levando as pessoas a reavaliar seus valores, atitudes e comportamentos e, certamente conduzirá a um processo de realinhamento coletivo muito mais produtivo e prazeroso (MUNARI \& BEZERRA, 2004).

Para que as relações interpessoais e grupais estabelecidas no processo de trabalho da enfermagem assumam o caráter profissional, diminuindo os traumas e as inadequações, é necessário que todos os 
envolvidos reconheçam a complexidade e o caráter processual, sistêmico e evolutivo dessas relações.

Quanto ao profissional de enfermagem, é necessário atualizar-se e instrumentalizar-se, no sentido de desenvolver habilidades necessárias para que ocupe, definitivamente, o lugar de destaque e o espaço ainda existente no campo da intersubjetividade.

É importante também pensar na responsabilidade dos cursos de graduação na representação de docentes e discentes, em favorecer um aprofundamento da questão relacional como uma das atribuições da enfermeira na liderança de uma equipe de trabalho, o que exige um conhecimento adequado, muitas vezes não priorizado durante a formação, e, também posteriormente, como profissional (URBANETTO \& CAPELLA, 2004).

\section{Propostas e Tendências de Gerência Contemporânea}

Propostas e Tendências de Gerência Contemporânea foi retratada em $60 \%$ dos artigos e trazem a reflexão de CIAMPONE \& KURCGANT (2004), de que a década de 90 foi extremamente produtiva para a enfermagem, tanto na área da produção científico-acadêmica, como na área da prática assistencial e gerencial. Porém na área do gerenciamento no que diz respeito aos saberes e fazeres específicos, a produção mostrou-se insuficiente, o que indica necessidade de se pensar formas alternativas de gerenciamento em saúde.

Para responder às demandas da problemática advinda do processo assistencial e, paralelamente, às demandas do processo gerencial, há que se rever e recompor os modelos de gestão, bem como, as competências inerentes à formação dos profissionais / gestores.

Neste contexto, é importante a participação da academia, juntamente com as organizações no sentido de repensar as intervenções necessárias, possibilitando visualizar as práticas e teorias relacionadas ao gerenciamento da assistência propiciando, portanto, a introdução da dimensão política no saber e no fazer crítico do gestor em saúde (CIAMPONE \& KURCGANT, 2004).

Constata-se que na enfermagem as transformações na formação dos profissionais não vem ocorrendo no mesmo ritmo às transformações na área, é um ritmo mais lento, atuando como resposta às exigências impostas pelo mercado de trabalho (CIAMPONE \& KURCGANT, 2004).

Essas constatações podem ser conseqüências do ensino das escolas, que ainda mantém inseridos nos conteúdos programáticos, ora focalizando o modelo tradicional de gerência, unidimensional e linear, ora contextualizando esses conteúdos com abordagens e visões de mundo mais abrangentes e modernas, compatível com as atuais políticas de saúde (CIAMPONE \& KURCGANT, 2004).

Portanto, conforme o autor acima, há necessidade de reformulação dos processos e práticas de formação profissional na área de Administração em Enfermagem. Aponta, ainda, para a importância do ensino contextualizado, priorizando aprendizagens significativas e fortalecendo o papel do aluno como sujeito de sua formação e da sua vida. Destaca, principalmente, a necessidade de preparação pedagógica dos docentes para atuarem de maneira efetiva na condução do processo de ensinoaprendizagem, adotando instrumentos diversificados, como o entendimento que o conjunto de saberes e fazeres é que consolidará a almejada identidade profissional dos enfermeiros.

De acordo com MUNARI \& BEZERRA (2004), na atualidade, as discussões e tendências na área da saúde apontam para a melhoria nos modelos de gestão orientada para os clientes, para o aperfeiçoamento do desempenho das instituições prestadoras desses serviços, quer na área pública ou privada.

Este processo requer dos profissionais de Enfermagem a ampliação de seus conhecimentos, bem como a busca contínua, de recursos e habilidades que possibilitem uma prática efetiva e inovadora de suas atividades sintonizada ao contexto de transformações da sociedade contemporânea.

Os debates desenvolvidos na área da saúde sobre a temática gerencial e os profissionais interessados nesse setor têm apontado a necessidade de realizar mudanças no modo de trabalhar em gerência, em todos os níveis das organizações de saúde, buscando as raízes históricas da Enfermagem, encontrando assim, alternativas que atendam às demandas atuais (MAGALHÂES \& DUARTE, 2004).

GRECO (2004) destaca que, na prática, os enfermeiros desempenham a função gerencial. As gerências de unidade e do cuidado estão diretamente associadas, uma vez que o enfermeiro ao gerenciar recursos em geral deve estar voltado para o processo assistencial e não deve se distanciar da qualidade da assistência.

O gerenciamento do cuidado não vem sendo realizado pelos enfermeiros e também não é cobrado pelas organizações, que dão maior ênfase ao gerenciamento das unidades de trabalho (GRECO, 2004).

Esta forma de trabalho tem ocasionado alienação do trabalhador e conseqüente limitação da iniciativa e da criatividade, formando um profissional sem reflexão, além de produzir insatisfação dos clientes, profissionais, descompromisso e baixa produtividade.

De acordo com MAGALHÃES \& DUARTE (2004), uma tendência atual que busca a quebra de paradigmas tradicionais de administração é a ênfase no capital humano das organizações. Sendo assim, acredita-se que a melhor forma do enfermeiro estimular seus funcionários é considerá-los como peças fundamentais deste processo, e como tal, investir no potencial de cada um, para alcançar os objetivos desejados. 
É necessário que as organizações tomem conhecimento da importância do desenvolvimento do capital humano através da implantação de organizações de aprendizagem, fundamental para desenvolver a capacidade de aprender das pessoas da própria organização, em todos os seus níveis e conseqüentemente melhora o desempenho. Torna-se indispensável exercer o raciocínio sistêmico, que permite as pessoas a aprender a entender o mundo de forma não fragmentada, ter noção integradora do todo, para poder assumir idéias inovadoras e romper as barreiras mentais que impedem as alterações organizacionais (MAGALHÂES \& DUARTE, 2004).

Em síntese, o que estas estratégias significam é que o enfermeiro, em sua prática de gerenciamento, deve aprender a lidar com o conhecimento do seu grupo. Este é um de seus desafios nos dias de hoje.

Uma estratégia já comentada é o desenvolvimento da liderança dos grupos de trabalho, que deve promover condições para um ambiente criativo. Outra proposta é a inovação operacional aplicada à Enfermagem que significa adotar maneiras novas de atender um cliente, realizar procedimentos, preencher um prontuário ou qualquer outra atividade, visando reduzir os custos, os erros e aumentar a produtividade (MAGALHÂES \& DUARTE, 2004).

Esse processo precisa ser estimulado, tanto nas instituições de saúde, como na graduação, numa tentativa de transformar os modelos tradicionais de ensino e práticas de gestão em Enfermagem. Deste modo, podemos ter um processo com repercussões na construção de novos conhecimentos de gestão em Enfermagem, introduzindo novos valores para a tomada de decisões, com reflexos em condições de trabalho e remuneração decentes, visando também autonomia e liberdade de exercer a profissão (MAGALHÂES \& DUARTE, 2004).

Uma perspectiva bastante atual de gerenciar o cuidado de enfermagem é através da disposição dos recursos necessários, preparar a equipe para oferecer uma assistência de qualidade, realizar auditorias com o objetivo de dar apoio às ações educativas e a revisão dos processos, oferecendo assim excelência ao cuidado (GRECO, 2004).

É preciso que pensemos novas tendências e possibilidades de gerência em enfermagem, sendo assim algumas proposições são colocadas: busca do novo e de uma postura de experimentação; gerência participativa, colocando o enfermeiro no centro de uma rede de decisões e não no ápice da pirâmide; buscar a flexibilização, com o rompimento do poder centralizado; administrar políticas, através de enfoque estratégico, visão global, perspectivas em longo prazo, construção de consenso, convencimento, compromisso, ética e transparência (GRECO, 2004).

É claro que essas propostas não serão concretizadas a curto prazo, até porque é necessário ter consciência de que implantá-las não é nada fácil, porém é preciso ter coragem que com muita luta, muitas mudanças podem acontecer.

A forma como o mercado tem se comportado frente a essas novas tendências de trabalho traz à tona a estratégia das cooperativas.

As cooperativas são formalmente definidas como sociedades que se constituem para prestar serviços a seus associados, visando o interesse comum e sem o objetivo do lucro. Podem ser formadas por vinte participantes no mínimo, denominados cooperados, que, ao ingressar, integralizam um capital em quotas (GUIMARÂES et al, 2004).

Muitas razões favorecem atualmente a disseminação do regime das cooperativas de trabalho no SUS: a) a vinculação de pessoal é feita de forma bastante flexível, através de um contrato global e, provavelmente, a custos mais reduzidos; b) promove uma condição de autonomia no mercado de trabalho; c) a condição de funcionário público é hoje muito pouco valorizada pelos profissionais de saúde; d) as tradicionais vantagens de remuneração diferenciada da aposentadoria no sistema de previdência pública foram anuladas; e) cria um vínculo coletivo de solidariedade entre os profissionais, o que obriga o gestor local do SUS a ter disposição para negociar os valores dos contratos e outros elementos que fazem parte das condições de trabalho (GUIMARÂES et al, 2004).

Algumas características, competências que o enfermeiro gerente deve possuir envolvem um saber apreendido no ambiente de trabalho, cujo conhecimento no processo de inserção no cargo poderá contribuir para a qualidade do seu trabalho. Isso sinaliza que é no interior do serviço e não fora dele, que o saber sobre gerenciamento pode ser construído e que os mesmos podem ser inclusos em processos educativos microlocalizados, a exemplo dos treinamentos introdutórios (MELO \& NASCIMENTO, 2003).

O treinamento introdutório na área da saúde tem como finalidade principal tornar o indivíduo apto para realizar tarefas específicas, e ele não deve ser encarado, como uma prática educacional relacionada à modelagem de comportamento e a aquisição de habilidade motora (MELO \& NASCIMENTO, 2003).

$\mathrm{Na}$ atualidade, a gerência em enfermagem deve ser entendida como um instrumento que contribui significativamente para que a assistência de enfermagem se torne um modelo de produção de serviço, que seja capaz de assegurar qualidade para toda a organização.

As tendências e propostas para a gerência de enfermagem contemporânea só terão aplicação se o próprio enfermeiro compreender que administrar também é cuidar. Além disso, o enfermeiro deve ter sempre em mente que um gerenciamento produtivo é aquele respaldado na confiança, no respeito e na valorização dos profissionais da equipe de enfermagem que ele lidera. Sendo assim, ele deve aprender a não caminhar sozinho, assumir os riscos e os desafios e transformar idéias e planos em ações (OLIVEIRA et al, 2004).

Dentre as várias estratégias de gestão que foram apresentadas pelos diferentes autores para lidar 
com essa complexidade, destacamos um movimento comum nas organizações modernas, que é a sua preocupação em trabalhar com o cliente interno, de maneira a ouvir suas sugestões, fazer com que participem das tomadas de decisões e desenvolvam um nível de satisfação crescente na organização. Neste caso os funcionários são os clientes internos e a utilização do endomarketing justifica-se pelo efeito direto na satisfação dos clientes externos, além do aumento da produtividade do funcionário em função do seu bem-estar (WEIRICH et al, 2004).

\section{CONSIDERAÇÕES FINAIS}

Embora a temática que envolva a questão da gerência e gestão dos serviços de enfermagem seja ampla, acreditamos que nosso estudo deixa alguns pontos importantes para reflexão acerca da formação de enfermeiros com maior satisfação profissional, com competência para gerenciar serviços de saúde, empregadores mais satisfeitos com o desempenho desses profissionais e, acima de tudo, clientes assistidos com mais dignidade e qualidade a que têm direito.

Tendo em vista que a Enfermagem passa por uma reforma curricular, entendemos que é o momento para reflexão sobre a responsabilidade que as instituições de ensino têm em formar e lançar no mercado de trabalho, profissionais para desempenhar ações gerenciais nos serviços de enfermagem e de saúde, que sejam comprometidos com 0 desenvolvimento de pessoas como forma de fortalecer as metas das organizações.

$\mathrm{Na}$ busca de referências em dois anos das REBEn`s percebemos que, as temáticas gerência e gestão em enfermagem são pouco trabalhadas no meio científico, pois dos treze artigos analisados, 11 pertenciam a uma edição temática da revista, os quais colaboraram muito para a construção deste estudo. Acreditamos ser necessária uma maior publicação de artigos referentes ao assunto abordado, pela sua relevância.

Compreendemos que para se realizar uma gerência de qualidade nos dias de hoje é preciso que se reconheça as transformações, no plano econômico, político e tecnológico que vêm passando as organizações de um modo geral, o que não é uma tarefa fácil e faz com que no campo da gerência também estejamos vivendo uma crise profunda, que leva a busca de uma mudança de paradigma.

\section{REFERÊNCIAS BIBLIOGRÁFICAS}

AlVES, M.; PENNA, C. M. M.; BRITO, M. J. M. Perfil dos Gerentes de Unidades Básicas de Saúde. Brasília (DF). Revista Brasileira de Enfermagem. V.57, n. 4, p. 441-446, 2004.

AZEVEDO, S. C. O Processo de Gerenciamento $x$ Gestão no trabalho do Enfermeiro. 2000. 24p. Dissertação de Mestrado em Enfermagem. Faculdade de Enfermagem, Universidade do Rio Grande do Norte, Natal (RN).

CIAMPONE, M. H. T.; KURCGANT, P. O Ensino de Administração em Enfermagem no Brasil: o processo de construção de competências gerenciais. Brasília (DF). Revista Brasileira de Enfermagem.V. 57, n.4, p.401-407, 2004.

FERNANDES, M. S. et al. A conduta gerencial da enfermeira: um estudo fundamentado nas teorias gerais da administração. Ribeirão Preto (SP). Revista Latino - americana de Enfermagem. V 11, n. 4, p. 161167, 2003.

GAIDZINSKI, R. R.; PERES, H. H. C.; FERNANDES, $M$.F. P. Liderança: aprendizado contínuo no gerenciamento em Enfermagem. Brasília (DF). Revista Brasileira de Enfermagem.V. 57, n.4, p.464-466, 2004. GIL, A. C. Como elaborar projetos de pesquisa. 4. ${ }^{a}$ ed. São Paulo: Atlas, 2002.

GRECO, R. M. Ensinando a Administração em Enfermagem através da Educação em Saúde. Brasília (DF). Revista Brasileira de Enfermagem.V. 57, n.4, p.504-507, 2004.

GUIMARÂES, R. M.; MUZI, C. D.; MAURO, M. Y. Tendências Modernas da Gerência do Trabalho da Enfermagem: o caso das cooperativas. Brasília (DF). Revista Brasileira de Enfermagem.V. 57, n.4, p.472474, 2004.

MAGALHÃES, A. M. M.; DUARTE, E. R. M. Tendências Gerenciais que podem levar a Enfermagem a percorrer novos caminhos. Brasília (DF). Revista Brasileira de Enfermagem.V. 57, n.4, p.408-411, 2004.

MELO, M. L. C.; NASCIMENTO, M. A. A .Treinamento Introdutório para Enfermeiras Dirigentes: possibilidades para gestão do SUS. Brasília (DF). Revista Brasileira de Enfermagem.V. 56, n.6, p.674677, 2003.

MUNARI, D. B.; BEZERRA, A. L. Q. Inclusão da Competência Interpessoal na Formação do Enfermeiro como Gestor. Brasília (DF). Revista Brasileira de Enfermagem.V. 57, n.4, p.484-486, 2004.

MUNARI, D. B.; MERJANE, T. V. B.; PRADO, M. A. A educação de laboratório no processo de formação do enfermeiro: estratégia para o desenvolvimento da competência. 2003.55p. [monografia de especialização] Sociedade Brasileira de Psicoterapia, dinâmica de grupos e psicodrama, Universidade Católica de Goiás, Goiânia (GO).

MYNAIO, M. C. S. (org). Pesquisa social: Teoria, método e criatividade. 6. ${ }^{\mathrm{a}}$ ed. Petrópolis (RJ) : Vozes, 1996.

OLIVEIRA, A. C. F. et al. Liderança e Enfermagem: elementos para reflexão. Brasília (DF). Revista Brasileira de Enfermagem.V. 57, n.4, p.487-489, 2004.

SIMÕES, A. L. A.; FÁVERO, N. Aprendizagem da liderança: opinião de enfermeiros sobre a formação acadêmica.Ribeirão Preto (SP). Revista Latino Americana de Enfermagem. V. 8, n.3, p.91-96, 2000. 
URBANETTO, J. S.; CAPELLA, B.B. Processo de Trabalho em Enfermagem: Gerenciamento das relações interpessoais. Brasília (DF). Revista Brasileira de Enfermagem.V. 57, n.4, p.447-452, 2004.

VAGHETTI, H. et al. Percepções dos enfermeiros acerca das ações administrativas em seu processo de trabalho. Brasília (DF). Revista Brasileira de Enfermagem.V. 57, n.3, p.316-320, 2004.

VALE, E. G.; GUEDES, M. V. C. Competências e habilidades no ensino de administração em enfermagem à luz das diretrizes curriculares nacionais. Brasília (DF). Revista Brasileira de Enfermagem.V. 57, n.4, p.475-478, 2004.

WEIRICH, C. F.; MUNARI, D. B.; BEZERRA, A. L. Q. Endomarketing: ensaio sobre possibilidades de inovação na gestão em enfermagem. Brasília (DF). Revista Brasileira de Enfermagem.V. 57, n.6, p.754757, 2004. 